\title{
A las barricadas!, uma versão brasileira: sobre a tradução coletiva
}

\section{A las barricadas!, a Brazilian version: on colective translation}

Paulo Henrique Pappen ${ }^{1}$ 


\section{Resumo}

Este artigo tem como objetivo relatar uma experiência tradutória coletiva com fins teatrais de uma canção anarquista espanhola chamada $A$ las barricadas!. Em um primeiro momento, procuro contextualizar a canção, expor a perspectiva teórica tradutória e apresentar o grupo de teatro GOTA, que surgiu em um curso livre no CEART/UDESC em 2018. Em um segundo momento, trago o texto-fonte e a tradução realizada pelo grupo teatral GOTA, tecendo comentários sobre essa experiência e suas reverberações no processo teatral do grupo.

Palavras-chave: Tradução teatral; tradução musical; anarquismo
Abstract

The goal of this paper is to report a collective translation experience for theatrical purposes of an anarchist Spanish song called $A$ las barricadas!. Firstly, I contextualize the song, I display the theoretical perspective and I introduce GOTA, theater group that emerged from a free course at CEART/UDESC in 2018. Then I present the source-text, the translation made by GOTA, and I comment about this translation experience and its echoes on the group theatrical process.

Keywords: Theatrical translation; musical translation; anarchism

E-ISSN: 2358.6958

Doutorando em Estudos da Tradução no Programa de Pós-Graduação em Estudos da Tradução - Universidade Federal de Santa Catarina (PGET/UFSC) paolopa@anche.no 
Este texto pretende ser um relato de uma experiência tradutória coletiva com fins teatrais. O objeto de tradução foi a canção $A$ las barricadas!. Trata-se de uma versão espanhola da canção polonesa Warszawianka ("Varsoviana"), de autoria desconhecida, mas que se tornou um hino anarquista graças ao poeta Waclaw Swiecicki (1848 - 1900) que, encarcerado em 1884 por lutar contra a ocupação russa na Polônia, compôs os versos em cima da melodia popular (Ossa Martínez, 2009, p. 317). Posteriormente, a canção se espraiou para outros territórios e ganhou versões em diversas línguas. A mais famosa, no Brasil, parece ser mesmo a versão espanhola, chamada A las barricadas! ("Para as barricadas!"), ou Marcha triunfal, que foi versionada em espanhol por volta de 1936 por Jacinto Torhyo (pseudônimo de Jacinto Torino Rodriguez, 1902-1989) e funcionou como um hino anarquista na Revolução Espanhola (1936-1939).

Neste trabalho, parto da ideia segundo a qual tradução, versão etc. são formas de reescrita que sempre "implicam um grau de manipulação do texto-fonte para um determinado propósito"2 (Hermans, 1985, p. 11). O termo versão é aqui entendido como uma forma de tradução que permite maior liberdade criativa: ou seja, é um trabalho que visa a um resultado mais próximo do contexto da língua e da cultura de chegada do que da língua e cultura de partida. Por exemplo, a língua de chegada no caso da experiência principal relatada neste artigo foi um português utilizado no Brasil, na medida do possível sem grandes marcas regionais. A cultura que se queria abarcar, portanto, era a cultura brasileira em amplo sentido (diferentemente da experiência mencionada rapidamente abaixo, de tradução de um poema de Lucía Sánchez Saornil, que privilegiou uma variante brasileira regional). Pode-se dizer que a finalidade era recriar no Brasil o hino anarquista a partir da canção espanhola, que por sua vez é uma versão da canção polonesa. A ideia era buscar uma versão que não gerasse estranhamentos regionais e que pudesse ser replicada por pessoas de norte a sul do país. Em resumo, versão é um tipo de tradução que busca adaptar um texto em um determinado contexto, sem que esse texto remeta necessariamente à sua origem. Ou seja, a consequência natural de uma versão é dar uma "vida própria" a uma tradução. Isso porque, como afirma Peter Low,

[...] um texto-canção precisa comunicar efetivamente à primeira audição. Isso dá uma primazia para a naturalidade da língua, porque a falta de naturalidade exige da audiência um esforço de entendimento adicional e supérfluo. $\mathrm{O}$ texto de chegada não vale a pena de ser feito a não ser que ele possa ser entendido enquanto a canção está sendo cantada. ${ }^{3}$ (Low, 2005, p.195-196)

Outros termos utilizados para se referir a essa modalidade tradutória são adaptação, tradução livre, paródia e localização. Trata-se, ao mesmo tempo, de uma estratégia e de um método tradutórios utilizados com relativa frequência no teatro e, também, quando o objeto tradutório é uma canção. Considere-se, a esse respeito, a

\footnotetext{
2 Em inglês no original: all translation implies a degree of manipulation of the source text for a certain purpose. (Todas as traduções neste artigo são de minha autoria).

3 A song-text must communicate effectively on first encounter. This places a premium on naturalness of language, because unnaturalness demands from the audience additional and superfluous processing effort. The TT is not worth making unless it can be understood while the song is sung.
} 
adaptação de Blasted, peça de Sarah Kane adaptada para o português brasileiro e localizada no Rio de Janeiro por Pedro de Senna (cf. Senna, 2009). Para uma discussão mais teórica, veja-se Hutcheon, 2013.

A tarefa tradutória com $A$ las barricadas! partiu do pressuposto segundo o qual a tradução para teatro tem especificidades: é fundamental considerar o contexto da apresentação, a época em que será apresentada a peça ou performance, a língua e as variedades linguísticas utilizadas etc. Isso, no entanto, não significa que o produto da tradução terá vida somente durante as performances; ele pode, também, ser publicado em forma de texto escrito e promover outro tipo de desfrute estético, como a leitura solitária e silenciosa. Contudo, o que entra em jogo na tradução para o teatro é essa dimensão da ação prática, da cena, do público, que a diferencia de traduções voltadas para a publicação em texto escrito, as quais, caso venham a ser encenadas ou performadas, precisarão no mais das vezes passar por um processo de adaptação, ou seja, de versão, de recontextualização: em uma palavra, de reescrita. Como afirma Susan Bassnett, no teatro

os diálogos são caracterizados pelo ritmo, padrões de entonação, tom e volume, todos elementos que podem não ser imediatamente aparentes em uma leitura direta do texto escrito em si. ${ }^{4}$ (Bassnett, 1991, p. 122)

Acrescente-se a isso que, para traduzir uma música, a questão do ritmo é ainda mais importante, dado que a métrica dos versos deve encaixar na melodia. Por isso nesses casos prefere-se falar em versão: porque as traduções de canções em geral se afastam bastante dos versos originais, mantendo apenas a métrica e recriando o sentido da letra. Como veremos, porém, a versão brasileira de $A$ las barricadas! ficou bastante próxima do original (original entendido aqui como sinônimo de texto-fonte, ou seja, a versão espanhola escolhida para ser traduzida).

Para além da especificidade de tradução teatral, há nesse caso também a especificidade da tradução musical, em que é preciso buscar um equilíbrio entre música e letra. De acordo com Dinda Gorlée, essa é

uma empreitada imaginativa, que cede à tentação de gerar uma simbiose tradutória de textos poéticos e musicais. A empreitada é caracterizada pelo logocentrismo e pelo musicocentrismo. O que se vê aqui, tanto quantitativa quanto qualitativamente, é o peso artístico relativo e a importância dada a ambos os elementos desse duplo construto simbiótico. ${ }^{5}$ (Gorlée, 2005, p. 8)

Ou seja, o desafio é não dar atenção especial a somente um dos aspectos - música ou letra - mas a ambos. Acrescente-se a isso o fato de a ideia da tradução ter surgido como um número teatral e temos um novo aspecto a considerar: a performance, que vai ser relatada na última seção deste artigo.

\footnotetext{
4 The dialogue will be characterized by rhythm, intonation patterns, pitch and loudness, all elements that may not be immediately apparent from a straightforward reading of the written text in isolation.

5 [...] an imaginative enterprise, yielding the temptation to bring out a translated symbiosis of poetic and musical texts. The enterprise is characterized as logocentrism and musicocentrism. What is seen here, both quantitively and qualitatively, is the relative artistic weight and importance given to either element of the double symbiotic construct.
} 
A ideia de realizar a tradução de $A$ las barricadas! surgiu no Curso Livre de Teatro e Anarquismo, no segundo semestre de 2018, ministrado por Cassiana dos Reis Lopes, doutoranda no Programa de Pós-Graduação em Teatro, no Centro de Artes da Universidade do Estado de Santa Catarina (CEART/UDESC). Nesse curso, que buscava identificar aproximações entre recursos teatrais e a ideologia anarquista, formou-se - Grupo Organizado de Teatro Aguacero (GOTA), que elegeu como proposta estética explorar a história e a ideologia do anarquismo (desde 1860 até os dias de hoje) como uma fonte dramática. Dois dos recursos mais utilizados pelo grupo são, de fato, a tradução e a música, fundamentais para a construção de números teatrais, ações e performances. $^{6}$

Como afirma Cassiana dos Reis Lopes, que iniciou uma importante pesquisa relacionando anarquismo e teatro na academia, trata-se de uma busca por

procedimentos e maneiras na arte/teatro de resistir ao terrorismo de Estado. [...]
O anarquismo atravessa a pesquisa no sentido da crítica ao que acredito ser a raiz
do problema do terrorismo de Estado, o próprio Estado, e nas práticas de resis-
tência e sobrevivência que o anarquismo vivenciou e vivencia em tempos e con-
textos de totalitarismo, a questão é como trazer isso para a arte. (Lopes, 2018, s/p)

O GOTA, então, surgiu como uma possibilidade de colaborar para construir respostas para essa questão: como trazer elementos anarquistas para a arte?

Elenco algumas ideias aqui. Em primeiro lugar, a própria formação de um grupo de teatro focado nessa relação entre anarquismo e teatro é já uma resposta social à conjuntura política nacional e internacional, especialmente à conjuntura de fins da década de 2010. Nesses tempos, pode-se identificar uma radicalização em diversas frentes: do ponto de vista da luta de classes, ou seja, um ponto de vista socialista (e o anarquismo é um tipo de socialismo libertário, cf. Correa, 2015, p. 117), há um entendimento de que avança a passos largos o projeto capitalista de precarização das condições de trabalho, redução drástica de direitos sociais e aprofundamento do Estado Policial, medidas essas que os governos têm tomado, de modo mais ou menos violento, em todas as partes do mundo. E aqui vem o ponto de vista capitalista: são medidas necessárias nesta etapa do sistema, uma espécie de contenção de despesas em larga escala para evitar que as próximas crises financeiras prejudiquem a classe dominante. Assim, nota-se uma diferença na concepção de sociedade possível: hoje não parece mais haver espaço para ideias por assim dizer "moderadas" como a noção de bem-estar social, bandeira social-democrata da segunda metade do século XX. Por isso, falar em radicalização da política em 2019 é falar do crescimento da extrema direita e seus ideais abertamente excludentes e violentos: negação da História (por exemplo, discursos sobre o nazismo ser de esquerda, cf. Ramalho, 2016), corte e alteração de direitos trabalhistas (como a terceirização e a "uberização", por exemplo, cf. Abílio, 2017), negligência em relação à destruição ambiental (os casos de Mariana, em 2015, e o de Brumadinho, em 2019, cf. CAB, 2019), o que vem acompanhado por um aumento do Estado Policial, ou seja, da repressão militar necessária para tentar controlar possíveis revoltas populares. A universidade pública não passa imune nesse

6 Não pretendo aqui entrar em uma discussão que aprofunde esses conceitos, pois é irrelevante para este relato de experiência tradutória. 
cenário e, mais do que nunca, tende a sofrer ataques e tentações para que se abra à "iniciativa privada" (Brasil, 2017; Centospé, 2019), enquanto se fecha para a classe trabalhadora e se torna um ambiente censurado, como durante as eleições de 2018 (Sayuri, 2018) e de modo ainda mais explícito com os cortes no orçamento e o sequestro das bolsas de pesquisa na pós-graduação, tanto em nível estadual (Azevedo, 2019), quanto em nível federal (G1, 2019).

Em meio a esse contexto, ocorreu em novembro de 2018, em Florianópolis, o I Colóquio Pesquisa e Anarquismo: perspectivas em debate, sediado na Universidade Federal de Santa Catarina (UFSC) e na Universidade do Estado de Santa Catarina (UDESC). Entendendo que o espaço era politicamente favorável, o GOTA resolveu apresentar números teatrais durante o evento, colocando então em prática a ideia de trazer elementos anarquistas para a arte e, ao mesmo tempo, levar elementos artísticos para o anarquismo.

Uma das ações realizadas pelo grupo foi a declamação de um poema da anarquista espanhola Lucía Sánchez Saornil (1895 - 1970), a leitura de uma carta da anarquista argentina Salvadora Medina Onrubia (1895 - 1972) e, evidentemente, a apresentação da versão brasileira de $A$ las barricadas!. Esses três números contaram com um primeiro momento que consistiu em traduzir coletivamente as obras originais (o poema, a carta, a canção) para o português brasileiro. Como o objetivo era a apresentação cênica desses textos, a escolha linguística privilegiava as variantes de português de quem iria atuar. Por exemplo, a pessoa que declamou o poema de Lucía Sánchez Saornil é praticante de uma variedade linguística em que na forma verbal do pretérito perfeito, na segunda pessoa do singular, acontece uma assimilação da oclusiva desvozeada / $t$ / devido à proximidade da fricativa desvozeada /s/, ou seja, nessa variedade as pessoas dizem "tu fosse" em vez de "tu foste". Assim, na tradução realizada pelo grupo, os versos de Lucía Sánchez Saornil continham marcas fonéticas regionais dessa variedade de português. $O$ mesmo se poderia falar sobre a carta de Salvadora Medina Onrubia, que foi lida por duas pessoas que adaptaram, de acordo com suas facilidades linguísticas, o texto a ser lido em voz alta. Isso faz parte de uma concepção tradutória que não busca uma homogeneização da língua e, pelo contrário, dá voz literalmente a variantes negligenciadas e vilipendiadas por uma visão normativa de língua baseada em certo e errado (cf. Garcez, 1999).

Esses exemplos dão uma ideia do que ocorre na tradução teatral, principalmente quando a estética buscada envolve uma aproximação da naturalidade coloquial: nesse caso, é importante que haja abertura para a variação linguística. Essa busca por naturalidade, esse fomento à utilização de variedades linguísticas pouco privilegiadas na arte, me parece possível graças a um método que eu chamo de "tradução libertária", ou seja, uma tradução permeada pela ideologia anarquista, que coloca em prática, na linguagem, princípios tais como o antirracismo, o antimachismo, o antifascismo e que dá espaço para formas linguísticas populares, muitas vezes dando voz a variedades de língua que tendem a ser apagadas como "erradas" por sofrerem preconceito de classe e cor. Isso se relaciona com o que pode ser chamado de "estética anarquista" (Rezsler, 1975), que procura identificar sempre uma função social nos projetos e objetos artísticos. Dentro dessa estética anarquista, há também uma 
tradição teatral que vem já do início do século XX no Brasil, conforme Samanta Colhado Mendes (2010, p. 219):

\begin{abstract}
o artista, nessa concepção, deveria estar comprometido com o social e sua transformação, sem colocar-se de maneira privilegiada ou como profissional mesmo na sociedade capitalista. [...] Esse teatro era composto por indivíduos, que, na maioria das vezes, não eram profissionais, com múltiplos "dons" (habilidade com pinturas e montagens de cenários - geralmente improvisados -, luzes, figurinos, sonoplastia, costuras e atuação) e que se reuniam livremente e pelo puro gosto pelo espetáculo e/ou compromisso com a propaganda, com a mensagem que se queria levar a um maior número de pessoas e, em segundo lugar, propunha o abandono da passividade, o que levava a intervenção do público no ato criador e na representação final.
\end{abstract}

A não profissionalização é, de fato, um traço importante quando se fala em montagem teatral aliada à tradução coletiva. A tradução muitas vezes, no senso comum, é vista como algo impossível ou, pelo menos, difícil, então existe uma tendência à profissionalização dessa atividade. Traduzir coletivamente um texto, portanto, pode ser uma abordagem contra o medo de se aproximar a um texto estrangeiro e torná-lo nosso. Pode ocorrer inclusive uma espécie de "expropriação", para usar um termo caro a anarquistas principalmente do século XIX: traduzir seria, assim, um modo de se apossar de algo que nos foi proibido e que reforça o poder de alguns poucos privilegiados.

Algumas integrantes do GOTA nunca haviam traduzido e, em comentários feitos durante o processo de tradução, afirmaram que a tarefa lhes pareceu mais fácil do que pensavam. De fato, é o que se espera que o trabalho coletivo propicie: a facilitação da realização de tarefas. A questão de o texto-fonte ser em espanhol, nesse caso, também parece ter tornado o trabalho menos complicado, pois as línguas portuguesa e espanhola são bastante próximas. Outro elemento facilitador da atividade foi o grupo compartilhar um certo conhecimento básico sobre a Revolução Espanhola (1936-1939), um evento importante na história do anarquismo, quando trabalhadores e trabalhadoras organizadas em sindicatos e outros coletivos implementaram a autogestão em fábricas e fazendas na Espanha, além de combaterem o exército fascista e seu general Franco (Oliver, 1978). A maior parte da militância anarquista na Espanha se organizava em sindicatos, unificados pela Confederación Nacional del Trabajo (CNT), e na Federação Anarquista Ibérica (FAI). É a essa Confederación que $A$ las barricadas! fazem menção em seus versos finais.

Todo processo tradutório começa na escolha do texto-fonte. Essa escolha nem sempre é simples, às vezes é preciso escolher entre uma versão ou outras, e foi o que ocorreu nesse caso: inicialmente traduzimos a partir da versão presente na tese de Marco Antonio de la Ossa Martínez sobre música na Revolução Espanhola (Ossa Martínez, 2009, pp. 316-7). No entanto, encontramos uma versão alternativa na internet (Alternativa, 2018) e optamos por ela. Abaixo coloco a letra tal como está em Ossa Martínez (2009) e, em seguida, apresento a versão utilizada como texto-fonte para o GOTA: 


\section{Marcha triunfal \\ ¡A Las barricadas!}

Waclaw Swiecicki \& Jacinto Torhyo

Negras tormentas agitan los aires,

nubes oscuras nos impiden ver, aunque nos espere el dolor y la muerte, contra el enemigo nos manda el deber.

El bien más preciado es la libertad. Hay que defenderla con fe y con valor.

Alta la bandera revolucionaria que del triunfo sin cesar nos lleva en pos.

Alta la bandera revolucionaria que del triunfo sin cesar nos lleva en pos.

¡En pie pueblo obrero, a la batalla! ¡Hay que derrocar a la reacción! ¡A las barricadas! ¡A las barricadas por el triunfo de la Confederación! ¡A las barricadas! ¡A las barricadas por el triunfo de la Confederación!

(Ossa Martínez, 2009, pp. 316-7)

Apresento agora o texto-fonte utilizado pelo Grupo Organizado de Teatro Aguacero.

Negras tormentas agitan los aires

nubes oscuras nos impiden ver

Aunque nos espere el dolor y la muerte contra el enemigo nos llama el deber.

El bien más preciado es la libertad hay que defenderla con fe y valor. Alza la bandera revolucionaria suena el triunfo de nuestra emancipación

Alza la bandera revolucionaria suena el triunfo de nuestra emancipación

En pie el pueblo obrero a la batalla hay que derrocar a la reacción ¡A las Barricadas! ¡A las Barricadas! por el triunfo de la Confederación. ¡A las Barricadas! ¡A las Barricadas! por el triunfo de la Confederación.

(Alternativa, 2018; Barricadas, 2018) 
O verso e a palavra em itálico indicam a variante escolhida pelo grupo teatral para traduzir. Essa escolha se deu principalmente pelo grupo julgar positivo o efeito de repetição, na terceira estrofe, do verso suena el triunfo de nuestra emancipación ("soa o triunfo da nossa emancipação", que na versão final ficou sem o pronome "nossa", por razões de musicalidade). Foi consensual também o entendimento de que o verbo llamar ("chamar"), na primeira estrofe, era mais adequado do que o verbo mandar ("mandar"), que está presente na versão de Ossa Martínez (2009).

Vejamos agora a tradução realizada pelo grupo.

\section{A las barricadas!}

Tradução Grupo Organizado de Teatro Aguacero

Brancas tormentas agitam os ares
nuvens cinzentas nos impedem de ver
Mesmo que enfrentemos a dor e a morte
contra o inimigo nos chama o dever
O bem mais precioso é a liberdade
vamos defendê-la com fé e valor
Ergue a bandeira revolucionária
soa o triunfo da emancipação
Ergue a bandeira revolucionária
soa o triunfo da emancipação
De pé, povo obreiro, para a batalha
vamos derrotar a reação
A las barricadas, a las barricadas!
pelo triunfo da Confederação
A las barricadas, a las barricadas!
pelo triunfo da Confederação

Chama atenção desde logo que optamos por não traduzir o título da canção. Isso se deveu ao fato de, no ambiente anarquista, a música ser conhecida pelo seu nome espanhol ${ }^{7}$. Além do mais, o significado da expressão a las barricadas é transparente (a não ser que as ouvintes não saibam o que é uma barricada, mas a canção não poderá dar conta de explicar isso). Uma alternativa seria traduzir por "para as barricadas", que encaixaria na métrica, mas essa ideia não agradou o grupo por duas razões: em primeiro lugar, porque isso parecia enfraquecer a referência cultural que anarquistas captam subitamente ao ouvirem a expressão a las barricadas, que é um dos ícones da Revolução Espanhola nesse circuito militante. Isto é, pareceu ao grupo que fosse inclusive positiva a manutenção do título e do verso principal do refrão

7 Embora exista pelo menos outra tradução para a mesma canção, que optou por "Para as barricadas". Essa outra versão que conheci recentemente é interpretada pelo grupo Juventude Maldita e não entrou na análise que apresento neste texto. Pode ser ouvida aqui: https://www.youtube.com/watch?v=AT2a_5AYhFY 
originais (considerando aqui original o texto-fonte, ou seja, a versão espanhola alternativa apresentada acima). Exemplos similares podem ser encontrados no cancioneiro traduzido brasileiro, como as versões de Mr. Tambourine Man de Bob Dylan estudadas por Maiaty Saraiva Ferraz (2017). Em segundo lugar, a expressão "para as barricadas" foi rejeitada por soar pouco natural como chamado, já que o natural no Brasil seria, no mínimo, contrair "para" em "pra", além de promover a crase entre o a final da preposição e o a inicial do artigo (portanto, "pras barricadas!"), o que, no entanto, não fecha com a métrica da letra. Ressalte-se que essa impressão de falta de naturalidade foi decisiva para a escolha do refrão, mas não teve um papel significativo no momento de optar pelo verso "mesmo que enfrentemos a dor e a morte", que traduz aunque nos espere el dolor y la muerte ("mesmo que esteja nos esperando a dor e a morte"). Aparentemente, no meio de uma estrofe os critérios são mais frouxos em termos de naturalidade e mais rígidos em termos de métrica (essa seria uma hipótese a ser investigada com mais dados, o que não é o escopo deste artigo). De qualquer forma, embora a forma "mesmo que enfrentemos", com esse verbo no subjuntivo, seja bastante incomum no Brasil, seu sentido é transparente.

Outra observação necessária é a nossa opção por mudar a referência negativa referente às cores no imaginário popular, que se manifestam nos dois primeiros versos: em espanhol, negras tormentas e nubes oscuras, que traduzimos por brancas tormentas e nuvens cinzentas. Por entendermos que a luta antirracista deve acontecer em todos os momentos e espaços, e que muitas vezes essa luta se faz contra nós mesmas, que reproduzimos sem perceber o racismo no discurso, decidimos colocar as cores branca e cinza como adjetivos negativos que caracterizam o céu na metáfora dos versos iniciais. Se trata, novamente, do método de tradução libertária, permeado pela ideologia anarquista. Assumimos que o texto-fonte não tinha intenção de ser racista (é de se acreditar que, por motivos de formação populacional e progresso nas pautas da esquerda, o debate antirracista esteja mais avançado no Brasil de 2019 do que na Espanha de 1936), portanto estávamos em uma posição temporal privilegiada para realizar essa tradução antirracista e não teríamos razão para não fazê-la (até porque a métrica de brancas e cinzentas encaixa bem onde havia negras e oscuras). Dessa forma, por meio dessa tradução teatral e musical, defendemos que é importante sim interferir ideologicamente nos textos.

A primeira performance teatral com nossa tradução de $A$ las barricadas! foi realizada como uma intervenção antes de uma roda de conversa, durante o I Colóquio Pesquisa e Anarquismo: perspectivas em debate, no dia 6 de novembro de 2018, no auditório da Faculdade de Educação da Universidade Federal de Santa Catarina. Antes da hora marcada para a palestra, cerca de dez pessoas do GOTA se posicionaram no auditório de modo a poder ocupar diversos pontos e, assim, ecoar a canção de modo descentralizado. Perto do palco, havia pessoas com violão, acordeom, flauta transversal e uma caixa de bateria. Algumas pessoas estavam caracterizadas como "anarquistas espanholas", ou seja, com lenços diagonais em preto e vermelho.

Nessa ocasião, o GOTA contou com a participação especial de uma pessoa natural da Guatemala, que iniciou a intervenção cantando $A$ las barricadas! à capela, em espanhol. Enquanto ela cantava, foram distribuídos panfletos com a letra em portu- 
guês. Assim, quando o grupo ampliado começou a tocar e cantar a canção, o público estava apto a acompanhar. Seguindo de acordo com a letra da música, que em determinado momento convoca "de pé, povo obreiro, para a batalha", o público foi convidado a cantar junto e, de fato, muitas pessoas participaram. No mesmo sentido, a música pede: "ergue a bandeira revolucionária", e foi possível ver algumas bandeiras rubro-negras flamejarem a partir desse verso.

Foi uma performance bastante simples que, por isso, gerou um efeito positivo no ambiente: de alguma maneira, reunir arte e política potencializa ambas. A arte em ambientes militantes tem também a virtude de lubrificar os momentos de tensão que são característicos desses espaços. Em contrapartida, incorporar um tema político militante a performances artísticas pode ser uma maneira de encorpar manifestações e ir na contramão de certa tendência niilista e individualista que não parece contribuir efetivamente para mudanças sociais que beneficiem a classe trabalhadora. $E$, para além da possibilidade de performance pública, a tradução coletiva já é uma atividade de empoderamento social na medida em que promove a troca de conhecimentos em grupo com um fim útil para uma comunidade ainda mais ampla. Afirmo, então, que uma maneira de tornar eficiente a radicalização política na arte, de um ponto de vista anarquista militante, é o trabalho coletivo.

Depois dessa primeira performance, o GOTA iniciou um processo de construção de um espetáculo teatral sobre trabalho. A estreia dessa peça, chamada Não pense em trabalho: crise!, ocorreu em Joinville, no dia $1^{\circ}$ de maio de 2019 . Naturalmente, $A$ las barricadas! faz parte do espetáculo.

\section{Referências}

ABÍLIO, Ludmila Costhek. "Uberização do trabalho: subsunção real da viração" In. Passa Palavra [Página web]. 19 de fevereiro de 2017. Disponível em: https://passapalavra.info/2017/02/110685/ Acesso em: 13 fev.2019

ALTERNATIVA. "Alternate versions". In: Wikipedia. Disponível em: https://en.wikipedia.org/wiki/Talk:A_las_Barricadas\#Alternate_versions Acesso em: 14 fev.2018

AZEVEDO, Sidney. "Corte de verbas na UDESC ameaça pesquisa e extensão, diz diretor". In: Aconteceu em Joinville [Página web]. 07 de maio de 2019. Disponível em: https://www.aconteceuemjoinville.com.br/2019/05/07/corte-de-verbas-da-udesc-ameaca-pesquisa-e-extensao-diz-diretor/ Acesso em: 11 maio 2019

BARRICADAS. "A las barricadas". In: Wikipedia [Página web]. Disponível em: https:// es.wikipedia.org/wiki/A_las_barricadas Acesso em: 14 fev. 2018

BASSNETT, Susan. Translation Studies. Londres: Routledge, 1991.

BRASIL. "Universidades públicas poderão cobrar por cursos de pós-graduação". In: Governo do Brasil. Disponível em: https://www.brasil.gov.br/noticias/educacao-e- 
-ciencia/2017/04/universidades-publicas-poderao-cobrar-por-cursos-de-pos-graduacao Acesso em: 13 fev. 2019.

CENTOSPÉ. "Como resolver os problemas de segurança pública na UFSC e por que é tão difícil aceitar a solução". In. Coletiva Centospé [Página web]. 11 de janeiro de 2019. Disponível em: https://centospe.libertar.org/2019/01/11/como-resolver-os-problemas-de-seguranca-publica-na-ufsc-e-por-que-e-tao-dificil-aceitar-a-solucao/ Acesso em: 13 fev. 2019.

FERRAZ, Maiaty Saraiva. "Traduções de Mr. Tambourine man no Brasil: da refração à retradução". In: Cadernos de tradução. Florianópolis, v. 37, n² 2, p.101-131, maio-agos., 2017.

G1. "Suspensão de bolsas de estudo da CAPES atinge todas as áreas e pode afetar pesquisas". In: G1 [Página web]. 09 de maio de 2019. Disponível em: https://g1.globo. com/educacao/noticia/2019/05/09/suspensao-de-bolsas-de-estudo-da-capes-atinge-todas-as-areas-e-pode-afetar-pesquisas.ghtml Acesso em: 11 maio 2019.

GARCEZ, Pedro. "Diversidade linguística: considerações para a tradução”. In: Trab. Ling. Apl. Campinas, v. 33, p. 59-70, jan-jun, 1999.

GORLÉE, Dinda L. "Prelude and Acknowledgements". In: Song and Significance: Virtues and Vices of Vocal Translation. Amsterdam/Nova lorque: Rodopi, 2005, p. 7-15.

LOPES, Cassiana dos Reis. "Entrevista". In: Agência de Notícias Anarquistas [Página web]. 26 de novembro de 2018. Disponível em: https://noticiasanarquistas.noblogs.org/post/2018/11/26/cassiana-experimentar-o-teatro-experimentar-o-anarquismo-mexer-e-remexer-e-ver-no-que-da/ Acesso em: 26 nov. 2018.

LEFEVERE, André. Translation, rewriting, and the manipulation of literary fame. New York: Routledge, 1992.

LOW, Peter. "The Pentathlon Approach to Translating Songs In: GORLÉE, Dinda L. Song and Significance: Virtues and Vices of Vocal Translation. Amsterdam / Nova lorque: Rodopi, 2005, p. 185-212.

MENDES, Samanta Colhado. As mulheres anarquistas na cidade de São Paulo: 18891930. Dissertação (Mestrado em História). Faculdade de História, Direito e Serviço Social. Franca: UNESP, 2010.

OLIVER, Juan García. El eco de los pasos. Barcelona: Ruedo Ibérico, 1978.

OSSA MARTÍNEZ, Marco Antonio. La música en la Guerra Civil española. Cuenca: Ediciones de la Universidad de Castilla-La Mancha, 2009. 
SAYURI, Juliana. "O comando que está caçando 'esquerdistas' nas universidades já perseguiu 181 professores". In: The Intercept Brasil [Página web]. 26 de outubro de 2018. Disponível em: https://theintercept.com/2018/10/26/universidades-censura/ Acesso em: 15 fev. 2019

ZAN, Dirce \& MAZZA, Débora. "Escola sem partido? É possível?". In: Jornal da Unicamp [Página web]. 05 de dezembro de 2018. Disponível em: https://www.unicamp. br/unicamp/ju/artigos/educacao/escola-sem-partido-e-possivel. Acesso em: 15 fev. 2019.

Recebido em: $11 / 05 / 2019$

Aprovado em: 22/06/2019 